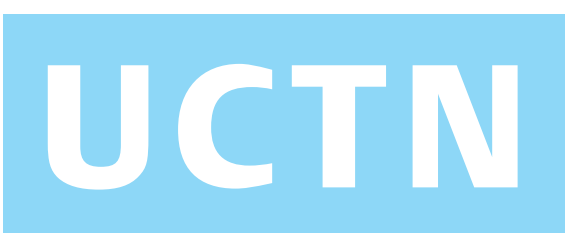

\title{
Endoscopic Clipping: A Useful Tool to Prevent Migration of Rectal Stents
}

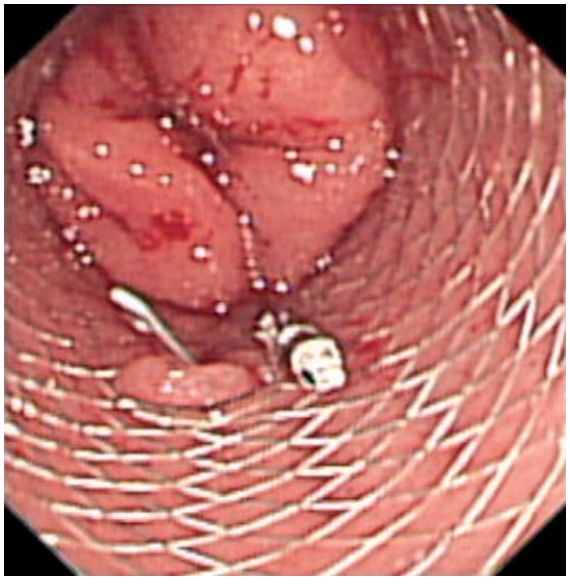

Figure 1 Endoscopic view of the stent with the clips in situ.

Self-expanding metallic stents are commonly used in the treatment of patients with obstructing colonic tumors, either for palliation or as an alternative to defunctioning ileostomy prior to radiotherapy [1]. One of the common problems encountered after stent placement is migration of the stent, which can occur in up to $14 \%$ of patients $[2,3]$. Stent migration can occur either spontaneously or as a result of the shrinkage of the tumor following radiotherapy [4].

Endoscopic clipping has been used previously to assist in the positioning of selfexpanding esophageal stents [5]. We applied endoscopic clips (HX-3L, Olympus, Hamburg, Germany) at the cranial and caudal ends of a metallic stent used in the treatment of patients with obstructing left colonic tumors (Figures 1,2). We did not encounter any stent migration in three patients in whom this technique was applied, with uncovered Ultraflex stents being used in all patients. We feel that endoscopic clips can be used effectively to prevent migration of self-expanding metal stents.

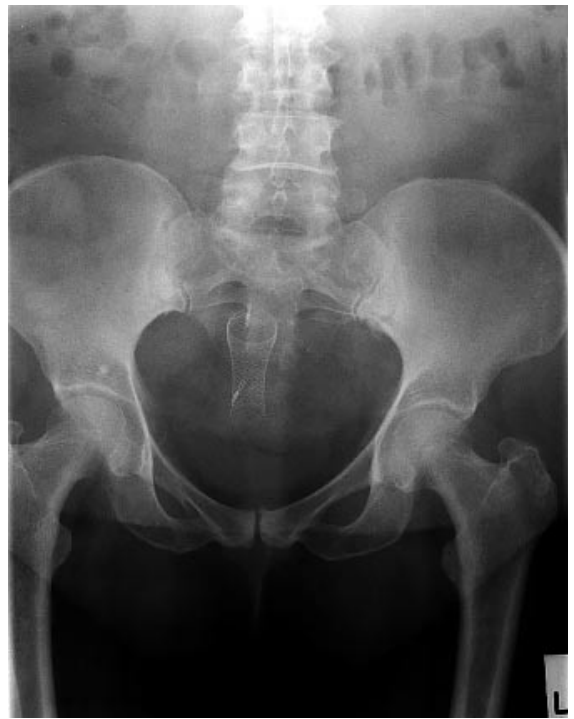

Corresponding Author

\section{Buckley, M.D.}

Department of Gastroenterology

Adelaide and Meath Hospital

Tallaght

Dublin

Ireland

Fax: $\quad+353-1-4143850$

E-mail: martin.buckley@amnch.ie
Figure 2 Abdominal radiograph showing the stent with the clips in situ.

\section{S. Sebastian, M. Buckley}

Department of Gastroenterology, Adelaide and Meath Hospital, Tallaght, Dublin, Ireland.

\section{References}

${ }^{1}$ Baron TH, Rey JF, Spinelli P. Expandable metal stent placement for malignant colorectal obstruction. Endoscopy 2002; 34: $823-830$

${ }^{2}$ Wong SY, Ng FH. Lower intestinal hemorrhage due to a dislodged metallic stent. Endoscopy 1997; 29: 407-408

${ }^{3}$ Law WL, Chu KW, Ho JW et al. Self-expanding metallic stent in the treatment of colonic obstruction caused by advanced malignancies. Dis Colon Rectum 2000; 43: 1522 - 1527

${ }^{4}$ Williams LR, Mitchell IC, Glynne-Jones R. Migration of endoluminal colonic stent following external beam radiotherapy. Clin Oncol (R Coll Radiol) 2003; 15: 35-36

${ }^{5}$ Segalin A, Bonavina L, Bona D, Chella B. Endoscopic clipping: a helpful tool for positioning self-expanding esophageal stents. Endoscopy 1995; 27: 34 